Check for updates

Mumbai, India

kanchansrivastava@gmail.com Cite this as: BMJ 2021;374:n2133 http://dx.doi.org/10.1136/bmj.n2133 Published: 03 September 2021

\section{Covid-19: Why has India had a spike in stillbirths?}

\section{India was making significant progress in reducing its stillbirth rate. But then covid-19 hit. Kanchan Srivastava reports}

\section{Kanchan Srivastava freelance journalist}

Pratiksha Gavali worked as a pathologist at Irwin Hospital in Amravati, Maharashtra, till last September, her eighth month of pregnancy. She tested positive for covid-19 in October. Later, she delivered a stillborn baby and died from the infection five days later.

Mumbai-based Sunita Chaurasia survived infection but mourns her stillborn child. She caught covid-19 during the last stage of pregnancy in March this year. "It was heart breaking that other corona affected women in my ward had babies in their arms but I didn't," she told The BMJ.

Hospitals across India have been reporting higher stillbirths and maternal mortality among covid-19 positive women during the country's second wave. A July study, conducted by the Indian Council of Medical Research (ICMR) and the National Institute of Research in Reproductive Health (NIRRH), also noted a higher frequency of severe covid-19 (8.5\% in second wave $v 1.7 \%$ in the first) and intensive care admissions among pregnant women (11.6\% of all intensive care admissions compared with $2.4 \%$ in the first wave), and more maternal deaths between February and May compared with the same period in 2020 (maternal mortality per 1000 births $83.3 \mathrm{~V}$ 10.2).

"Many hospitals refuse to assist in delivery unless women have a covid-19 negative certificate," says Vandana Srivastava, a Lucknow resident who was denied admission by many hospitals when she went into labour last November. Certificates are documents given by a diagnostic laboratory or government centre after a polymerase chain reaction (PCR) test.

India had made substantial progress in reducing its stillbirth rate over the past two decades-a 53\% reduction (from 29.6 per 1000 live births to 13.9 between 2000 and 2019 according to a Unicef report). ${ }^{1}$ But the pandemic threatens to reverse those hard fought gains.

The number of stillbirths (classified by the World Health Organization as a baby who dies after 28 weeks of pregnancy before or during birth) among mothers infected with covid-19 doubled in the second wave: according to Unicef, 34 per 1000 live births between February 2021 and May 2021 compared with the first wave that saw 15 per 1000 live births between April 2020 and January $2021^{2}$-and even that was significantly higher than the 13.9 recorded in 2019.

\section{Maternal and fetal mortality during the pandemic}

Unsurprisingly, maternal and fetal outcomes have worsened worldwide during the pandemic, with an increase in maternal deaths, stillbirth, ruptured ectopic pregnancies, and maternal depression, according to a review in the Lancet. ${ }^{3}$

WHO says pregnant women are not at high risk of increased risk of developing the severe form of the disease if they are infected, compared with non-pregnant women of a similar age. Women who contract covid-19 during pregnancy are 50\% more likely to experience premature birth and pre-eclampsia, and require intensive care. The risk of maternal mortality was 22 times higher than those without covid, according to the Intercovid study, published in JAMA Paediatrics in April, which looked at nearly 2100 Intercovid women in 18 countries. ${ }^{5}$

Intercovid also noted that $11.5 \%$ of babies born to infected mothers were covid-19 positive (it was unclear whether the babies contracted the virus during delivery or through placental transmission).

The July ICMR-NIRRH study found that the case fatality rate (CFR) of covid-19 for mothers increased eightfold from $0.7 \%$ to $5.7 \%$ in the second wave compared with the first. (India's overall reported CFR is $1.34 \%$, though it peaked at $3 \%$ in June $2021 .^{6}$ ) Rahul Gajbhiye, a scientist at NIRRH and co-author of the study, acknowledges that it is based on an observational study of 1200 women at one covid designated facility in the Mumbai region. "Whether covid-19 is the exclusive cause for stillbirth in these women was not investigated," he said.

\section{If not covid, then what?}

Although covid-19 itself remains a worry, the suspicion is that it is the disruption to maternal care that is behind the rise in stillbirths during the pandemic. Nutrition, for instance, could be a factor-over $77 \%$ of Indian households were consuming less food in 2020 (during the pandemic and lockdown) than before and food insecurity was higher among women, Muslims, Scheduled Castes, and people with lower education, according to a report by Azim Premji University based on a survey on 5000 workers across the various sectors. ${ }^{7}$ A study published in Global Food Security in March 2021 estimated that Indians eat a diet that costs roughly \$1 (£o.73; €o.85) per day-roughly a fifth of the cost of the least expensive healthy diet recommended by the EAT-Lancet Commission. ${ }^{8}$

The loss of jobs during the lockdown has cut household spending for millions of people, and a study published in Economia Politica showed that Indian women's dietary diversity declined during the lockdown compared with the same period in 2019, getting covid-19. ${ }^{4}$ It acknowledges, however, an 
showing decreased consumption of meat, eggs, vegetables, and fruit. ${ }^{9}$

But the biggest problem is the disrupted healthcare system. "Bad obstetric outcomes are a result of severe covid in the last stage of pregnancy and not because of the virus doing any harm to the pregnancy," says Able Lawrence, professor of clinical immunology and rheumatology at Sanjay Gandhi Post Graduate Institute of Medical Sciences, Lucknow, India.

WHO recommends at least eight prenatal check-ups, one ultrasound before 24 weeks of pregnancy, and daily intake of iron and folic acid supplements to prevent stillbirth. All will have been interrupted by lockdowns and the severe strain on the medical system. Unicef warns that 200000 more stillbirths will be recorded over the next year in 117 low and middle income countries because of severe covid related disruptions in healthcare services.

Over half of women of reproductive age in India are anaemic and a quarter are undernourished, according to Unicef. Iron and calcium supplements and prenatal check-ups are provided free to pregnant women by the federal government. Most women could not access these services, however, because of the closure of most centres and fear of catching the virus. That said, Gajbhiye says, "Anaemia is unlikely to have contributed to more severity and high case fatality in the second wave as the proportion of anaemic women was found to be almost the same (about 6o\%) in both waves."

It's more likely that poor access to healthcare-and the inequalities that have been sorely exposed by the pandemic-led to increases in stillbirth. Indicators of socioeconomic deprivation and poor access to healthcare facilities in rural and remote areas are strongly associated with an increase in stillbirth. An Indian study published in The BMJ in 2018 noted that incidence of stillbirth was high in rural areas and among women who were illiterate, poor, in unpaid employment, or who belonged to socially disadvantaged and minority communities. ${ }^{10}$

"During the pandemic, many facilities were converted completely to covid care," says Yogini Khanolkar, a lobbyist for the Village Social Transformation Foundation, which campaigns on behalf of minority ethnic communities in Nandurbar, one the poorest districts of India. "Many pregnant women were unable to receive timely care as a covid negative certificate was required for delivery. Even the ambulance service that each woman is entitled to at the time of delivery was affected. The ensuing chaos impacted the health of these women and their babies."

There is no quick fix for such deep rooted problems. But the federal government has been trying several schemes over the past 15 years. These include Pradhan Mantr Surakshit Matritv Abhiyan that guarantees a minimum package of antenatal care services to women in their second and third trimesters at designated government health facilities. In 2019, several different initiatives were brought together under a single scheme called SUMAN that assures free maternal and newborn healthcare to all women attending public healthcare facilities. There are also nutritional programmes at the state level.

"Surakshit Matritv Abhiyan, free nutritious meals provided at Anganwadi centres, and free prenatal care schemes supported by Unicef and the non-governmental organisation Plan India offer a great support to underprivileged pregnant women," says Khanolkar. But she warned that many of these schemes were affected by the lockdowns and have still not resumed at most places. "Since a large number of women and men are out of jobs because of the pandemic, these schemes are far more important now than when they started," she told The BMJ.
And the pandemic, of course, is far from over, she says. "The government must ensure that essential healthcare services are not affected by future waves."

"Civil society has fought for years to ensure institutional deliveries but perhaps the pandemic experience says we need to decentralise the maternity services. Training should be provided to midwives so that they can handle home deliveries in a crisis."

\section{Commissioned, not externally peer reviewed}

Competing interests: I have read and understood BMJ policy on declaration of interests and have no relevant interests to declare.

Unicef. A neglected tragedy: the global burden of stillbirths. October 2020. https://data.unicef.org/resources/a-neglected-tragedy-stillbirth-estimates-report.

2 Mahajan NN, Pophalkar M, Patil S, etal. Pregnancy outcomes and maternal complications during the second wave of coronavirus disease 2019 (covid-19) in India. Obstet Gynecol 2021. doi: 10.1097/AOG.0000000000004529 pmid: 34233345

3 Chmielewska B, Barratt I, Townsend R, etal. Effects of the COVID-19 pandemic on maternal and perinatal outcomes: a systematic review and meta-analysis. Lancet Glob Health2021;9:e759-72. doi: 10.1016/S2214-109X(21)00079-6 pmid: 33811827

4 WHO. Coronavirus disease (covid-19): pregnancy and childbirth. 2 September 2020. www.who.int/news-room/q-a-detail/coronavirus-disease-covid-19-pregnancy-and-childbirth.

5 Villar J, Ariff S, Gunier RB, etal. Maternal and neonatal morbidity and mortality among pregnant women with and without covid-19 infection: the INTERCOVID multinational cohort study. JAMA Pediatr 2021;175:817-26. doi: 10.1001/jamapediatrics.2021.1050 pmid: 33885740

6 India's covid-19 case fatality rate. Reuters. https://graphics.reuters.com/HEALTH-CORONAVIRUS/INDIA-DEATH/xklvyxmropg/index.html.

7 Lahoti R, Abraham R, Kesar S, et al. Covid-19 livelihoods survey. Azim Premji University 2020. https://cse.azimpremjiuniversity.edu.in/wp-content/uploads/2020/06/Compilation-of-findingsAPU-COVID-19-Livelihoods-Survey_Final.pdf.

8 Gupta S, Vemireddy V, Singh DK, Pingali P. Ground truthing the cost of achieving the EAT Lancet recommended diets: Evidence from rural India. Glob Food Sec 2021;28:100498. doi: 10.1016/j.gfs.2021.100498 pmid: 33738190

9 Gupta S, Seth P, Abraham M, Pingali P. Covid-19 and women's nutrition security: panel data evidence from rural India. Econ Polit 2021. doi: 10.1007/s40888-021-00233-9

10 Altijani N, Carson C, Choudhury SS, etal. Stillbirth among women in nine states in India: rate and risk factors in study of 886,505 women from the annual health survey. BMJ Open 2018;8:e022583. doi: 10.1136/bmjopen-2018-022583 pmid: 30413502

This article is made freely available for use in accordance with BMJ's website terms and conditions for the duration of the covid-19 pandemic or until otherwise determined by BMJ. You may use, download and print the article for any lawful, non-commercial purpose (including text and data mining) provided that all copyright notices and trade marks are retained. 